\title{
Changes in self-regulatory cognitions as predictors of changes in smoking and nutrition behaviour
}

\author{
Urte Scholz ${ }^{\text {* }}$, Gabriel Nagy ${ }^{\mathrm{b}}$, Wiebke Göhner ${ }^{\mathrm{c}}$, Aleksandra Luszczynska ${ }^{\mathrm{d}}$ and \\ Matthias Kliegel ${ }^{\mathrm{e}}$ \\ aDepartment of Psychology, Social and Health Psychology, University of Zurich, Zurich, \\ Switzerland; ${ }^{b}$ Max-Planck-Institute for Human Development, Berlin, Germany; ${ }^{c}$ Institut für \\ Sport und Sportwissenschaft, Universität Freiburg, Freiburg, Germany; ${ }^{d}$ University of Sussex \\ and Warsaw School of Social Psychology, Brighton, United Kingdom; ${ }^{\circ}$ Dresden University of \\ Technology, Dresden, Germany
}

\begin{abstract}
Most longitudinal, correlational studies on health-behaviour change examine effects of Timel social-cognitive predictors on subsequent behaviour. In contrast, our research focusses on associations between changes in predictors with change in behaviour. The Health Action Process Approach (HAPA) distinguishes between motivational predictors for intention formation and volitional predictors for behavioural change and served as theoretical basis. Two online-studies were launched targeting different behaviours (low-fat diet, smoking), different samples (Study 1: $N=469$; Study 2: $N=441$ ) and different time spans (Study 1: 3 months, Study 2: 4 weeks). Data were analysed by means of structural equation modelling with latent difference scores. Both studies resulted in almost parallel prediction patterns. Change in risk awareness and change in outcome expectancies did not result in change in intentions, whereas change in self-efficacy was of crucial importance. Change in behaviour was associated with change in action planning and action control over and above the effects of intentions. In one study, increases in self-efficacy yielded increases in behaviour change. Results demonstrate that change in action planning and especially action control was of great importance for behaviour change across two different behaviours. Analysing change in social-cognitive predictors allows drawing precise conclusions for interventions.
\end{abstract}

Keywords: health-behaviour change; self-efficacy; action planning; action control; nutrition, smoking

\section{Introduction}

Together with physical inactivity, both poor diet and smoking contribute almost equally to the largest number of deaths in the USA (Mokdad, Marks, Stroup, \& Geberding, 2004, 2005). Poor dietary habits can lead to overweight and obesity for which prevalence rates are increasing worldwide (World Health Organisation, 2006). Overweight is mainly caused by an energy imbalance over a longer time period. As fat is the nutrient with the highest amount of calories per gram, eating a low-fat diet is seen as one of the means to reduce

\footnotetext{
*Corresponding author. Email: urte.scholz@psychologie.uzh.ch
} 
energy intake effectively (e.g. Schweizerische Gesellschaft für Ernährung, 2007). Success rates of changing one's diet, however, are rather disillusioning: Most people who initially change their diet and lose weight have difficulties maintaining their healthier behaviour over a longer period of time (e.g. Ayyad \& Andersen, 2000).

Smoking is an important risk factor for a variety of lethal diseases, such as cardiovascular disease, cancer, etc. In 2006, almost one-third $(29 \%)$ of Swiss adults between 14 and 65 years of age smoked regularly (Keller, Krebs, Radtke, \& Hornung, 2007). More than half $(53 \%)$ of the regular smokers report intentions to quit smoking and of those, $41 \%$ report having had at least one unsuccessful quit attempt (Keller, Willi, Krebs, \& Hornung, 2004). Thus, investigating possible determinants of changing these risk behaviours is of high relevance and was one aim of the present research.

The widely used social-cognitive theories such as the Theory of Planned Behaviour (TPB; Ajzen, 1991) and Protection Motivation Theory (Maddux \& Rogers, 1983) commonly specify behavioural intentions as the proximal, and thus most important, predictor of behaviour. Unfortunately, intentions alone do not suffice for successfully changing one's behaviour. Empirical evidence for the gap between intentions and behaviour is given by several meta-analyses (e.g. Webb \& Sheeran, 2006). These studies indicate that intentions leave a large amount of variance unexplained in behaviour or behaviour change. This is insufficient not only from a scientific view but also from a practical view that aims at effectively supporting people to change their unhealthy habits. Including additional predictors for behaviour should help to better understand the process of behavioural change and enable effective interventions for fostering behaviour change.

For the present research, the Health Action Process Approach (HAPA; Schwarzer, 1992) served as the theoretical background model as it specifies several predictors for behaviour change besides behavioural intentions, which is in contrast to prevailing theories (such as the TPB, Ajzen, 1991). The HAPA differentiates between two phases in the process of behaviour change: a motivational phase that includes formation of behavioural intentions and a volitional phase, which starts right after an intention has been set and which includes the translation of this intention into behaviour.

In the HAPA, predictors of behavioural intentions are risk awareness, positive and negative outcome expectancies, and self-efficacy. Risk awareness is defined as the perceived personal vulnerability to a health threat. Perception of one's own risk is often the starting point of the formation process for health behaviour intentions (Weinstein, 2003), as it can bring people to deliberating health behaviour change. However, risk awareness alone is usually not a powerful predictor of intentions let alone health behaviour change (Ruiter, Abraham, \& Kok, 2001). A second factor for explaining intention formation in the motivational phase is outcome expectancies. It is assumed that the higher the perceived advantages (i.e. positive outcome expectancies) of a health behaviour change and the lower the perceived disadvantages (i.e. negative outcome expectancies), the more likely people are to build an intention to change their behaviour. The third predictor of intentions specified in the HAPA is self-efficacy, which is defined as a person's perceived capability to master arising demands and tasks successfully (Bandura, 1997). Someone who lacks confidence in being able to implement certain behaviour is less likely to form a behavioural intention. Whereas the other variables are assumed to unfold their effects on one of these criteria only (cf Lippke, Ziegelmann, \& Schwarzer, 2004), self-efficacy is assumed to be crucial for both intention formation and change in behaviour. This is in line with assumptions of Bandura's Social-Cognitive Theory (Bandura, 1997). For example, after having formed 
an intention, a self-efficacious person might initiate and maintain behaviour change with less difficulty than a person low in self-efficacy.

With formation of a positive intention, a person enters the volitional phase to act upon this intention. In the HAPA, action planning and action control are seen as crucial for behaviour change. 'Action planning' or implementation intentions (Gollwitzer, 1999) stand for forming concrete plans about when, where, and how to implement the intended behaviour. Many studies investigating the effects of action planning on different behaviours could demonstrate its usefulness for behaviour and behaviour change (Gollwitzer \& Sheeran, 2006). Planning is generally understood as a means to simulate behaviour mentally and prospectively, in order to be prepared for situations in which the behaviour should be performed (Ward \& Morris, 2005).

Another volitional construct that has been shown to be a powerful predictor of health behaviour change is 'action control' (e.g. Sniehotta, Scholz, \& Schwarzer, 2005). Action control is based on the idea from cybernetic self-regulation models (Carver \& Scheier, 1998) and comprises three sub-facets: awareness of standards, self-monitoring and self-regulatory effort. Awareness of own standards means that an individual is constantly aware about what their intentions were in terms of behaviour change (e.g. to eat a low-fat diet instead of junk food). Without the awareness of own standards, self-regulation failure becomes more likely (Baumeister, Heatherton, \& Tice, 1994). Self-monitoring refers to the process of monitoring one's own behaviour in order to evaluate whether further regulatory effort is necessary to reduce possible discrepancies between one's actions and intentions (having not eaten a low-fat diet the whole week). If self-monitoring capacity is lowered, for example, in stressful situations, self regulation failures may result (Baumeister et al., 1994). Finally, if discrepancies between one's own actions and intentions are perceived, self-regulatory effort must be invested by applying discrepancy-reducing means. These three facets of action control can either be considered separately or combined in a second-order factor. The importance of action control in prediction of health behaviour has been confirmed in longitudinal correlation studies (e.g. Sniehotta et al., 2005) and randomised controlled trials (e.g. Schüz, Sniehotta, \& Schwarzer, 2007).

\section{Change in motivational and volitional variables}

Most studies in the area of health behaviour change apply a two-wave research design that comprises social-cognitive predictors, and measures of behaviour at baseline and follow-up. In these studies, baseline levels of social-cognitive predictors are tested for their ability to predict behaviour at Time 2 either with or without controlling for behaviour at baseline.

Even though findings from such investigations are important from a theoretical perspective, their results are often interpreted as evidence for eliciting social-cognitive variables that need to be changed by interventions in order to foster behaviour change. Such an interpretation may be forejudged because this conclusion is drawn without observing whether change in social-cognitive variables themselves is indeed associated with change in behaviour. Moreover, it is no logical necessity that in the case where baseline measures predict subsequent behaviour, there are also associations between changes in social-cognitive variables and change in behaviour. Thus, testing this implication within a correlational design would require investigating whether actual change in motivational and volitional variables indeed leads to or at least covaries with changes in intentions and with change in behaviour. 


\section{Aims and hypotheses}

The aim of our research was two-fold: First, to test whether changes in motivational and volitional variables as specified in the HAPA emerge as predictors of change in intentions and change in behaviour, respectively. Testing the associations between change in socialcognitive variables and change in behaviour is crucial for identifying the important variables to be targeted in interventions. And second, to test the application of the HAPA to two behaviours (low-fat diet and smoking) that have not yet been investigated under this theoretical framework.

We expected that the prediction pattern formulated in the HAPA model holds for the level of change scores for both types of behaviour. In particular, hypotheses for both studies were the following:

(1) Change in risk awareness, outcome expectancies and self-efficacy predict change in behavioural intentions.

(2) Change in behaviour is predicted by change in self-efficacy and intentions.

(3) Over and above the effects of changes in intentions and self-efficacy, changes in action planning and action control contribute substantially to change in behaviour.

\section{Data analyses in Studies 1 and 2}

One of the major problems with the use of observed difference scores is their typical low reliability (Plewis, 1985). In order to avoid such problems, we specified latent difference scores. That is, we investigated associations on the level of 'true' differences by specifying changes in a latent variable framework. Investigating change in psychological constructs requires invariant measurement procedures across time points. It needs to be ensured that the observed measures are linked to the underlying constructs they are intended to measure in the same way on every occasion (e.g. Bereiter, 1963). There are different statistical tools that might be used to investigate the degree of measurement invariance given. One frequently used approach is confirmatory factor analysis (CFA; Jöreskog, 1969). CFA is a flexible tool that allows investigating different levels of invariance.

Three levels of invariance can be distinguished (Meredith, 1993) and are especially important in the present study. First, 'configurable invariance' is a requirement for the assumption that the measures represent the same constructs on every occasion. Configurable invariance is said to be given when the same factors emerge at every occasion. This situation is indicated by qualitatively invariant patterns of loadings across occasions. Second, 'weak invariance' or 'loading invariance' is a requirement for the assumption that the latent factors are expressed on the same metric. Weak invariance implies that the impact of latent factors on observed scores is the same on every occasion. As a consequence, factor loadings are numerical invariant across occasions. Third, 'strong invariance' is said to be given when the measurement intercepts of observed indicators are invariant across time in addition to the loading matrices. Strong invariance is a prerequisite to capture change on an absolute level. For the purpose of the present investigation, it is thus important to establish strong measurement invariance.

In our CFA model, we impose no restrictions on the factor correlations. That is, we freely estimate the latent correlations within and across occasions. In contrast, we assume that unique scores are uncorrelated within occasions, because the only reliable information represented by these variables is assumed to be item specific. However, we additionally introduce cross-time correlations between the uniquenesses belonging to the same item across occasions (see also Jöreskog, 1979). 
Factor means at the first occasion are specified to be zero and all intercepts are estimated (although they are constrained to be equal across time points to ensure strong invariance). The factor means at the second occasion are freely estimated. The means thus directly represent the mean change in latent constructs across time.

The change model is derived by regressing the Time 2 factors on the Time 1 factors while constraining the regression weights to values of one and including additional factor disturbances $(\Delta s)$ with freely estimated means and (co)variances into the model. $\Delta s$ directly represent latent or 'true' differences. Specifying differences on the level of latent factors has the advantage of representing absolute change on the level of error-free common scores (McArdle, 2001). By doing so, the problem of typically low reliabilities of difference scores (e.g. Plewis, 1985) is circumvented.

The latent change model provides estimates of variance components of latent changes. Statistically significant change variances indicate the existence of interindividual differences in intra-individual change. Clearly, individual differences in change constitute prerequisites for the present study. Second, the change model additionally provides covariance estimates between change factors. These covariances are the basis for specifying directed effects across change factors in the next step of model modification.

Data in both studies were analysed by means of structural equation modelling using Mplus 4.1 (Muthén \& Muthén, 1998-2006). Model fit was assessed by examining $\chi^{2}$, the comparative fit index (CFI), and the root-mean-square error of approximation (RMSEA). A satisfactory model fit is indicated by high CFI $(>0.90)$, and low RMSEA $(<0.08)$. The $\chi^{2}$ of the model, however, is a sample-size dependent index. Therefore, it cannot be considered as a basic criterion for the acceptance or rejection of a model (Kline, 2005).

In most longitudinal studies, the problem of missing data occurs. Complete deletion of persons with missing values is only appropriate when the missing pattern meets the assumption of missing completely at random (MCAR; Little \& Rubin, 2002). MCAR means that the dropout is a random subsample of the study sample without any systematic association between missings and observed values. Missing at random (MAR) is a weaker assumption than MCAR for missing patterns and means that the probability of missing values depends on the observed values. Under MAR, the Full Information Maximum Likelihood technique (FIML; Arbuckle, 1996), which is an integral part of Mplus, results in unbiased parameter estimates (Enders \& Bandalos, 2001). FIML is a method that uses all available information of all observed (including incomplete) cases in order to enhance the validity of parameter estimation. FIML is superior to common methods such as listwise or pair-wise deletion (Enders \& Bandalos, 2001); this is why FIML was chosen for the present study.

\section{Study 1: Changing nutrition habits to eat a low-fat diet Design and sample}

Data were collected online in the context of the commercial web-based nutrition programme 'eBalance' (www.ebalance.ch). EBalance aims at assisting people with longterm nutrition change by means of an online diet-diary, feedback on weight change over time, recipe suggestions, and weekly 'coaching letters'. The online study was advertised on the eBalance-webpage ${ }^{1}$ and only active members of the programme were invited and able to join the study. After giving informed consent online, participants filled out the first online questionnaire. Three months later, participants were automatically invited by email 
by means of the online questionnaire programme 'Netquestionnaires' to complete the second online questionnaire.

Overall, of 2981 registered (i.e. not necessarily active) participants of the eBalanceprogramme, 469 respondents (16\% of registered participants) filled out the first questionnaire $^{2}$, with $344(73.3 \%)$ completing T2 measures. Of the 469 participants, 384 $(81.9 \%)$ were women; mean age was $44.25(S D=12.40$; range $18-79)$ and mean body mass index (BMI) was $27.44(S D=4.83)$. Most of the participants were married or living in a domestic partnership $(n=325 ; 69.3 \%), 97$ persons $(20.7 \%)$ were single, $36(7.7 \%)$ were divorced and 11 persons $(2.3 \%)$ were widowed. In terms of schooling, 462 persons $(98.7 \%)$ attended 12 or 13 years of school; 5 persons $(1.1 \%)$ attended 9 years, and 2 persons $(0.4 \%)$ did not indicate their years of schooling.

Dropout analyses revealed no differences in sex, BMI or education, nor on most core variables used in the study between dropouts $(n=125)$ and continuers $(n=344)$. There was a mean difference in intentions to eat a low-fat diet $(F(1,464)=5.02, p<0.05)$ and action control $(F(1,454)=4.98, p<0.05)$, in that dropouts reported lower levels of intentions $(M=3.23, S D=0.76)$ than continuers $(M=3.39, S D=0.70)$ as well as lower levels of action control $(M=3.08, S D=0.66$ compared to $M=3.22, S D=0.59)$. However, this systematic dropout on core variables of the study can be accounted for by the FIML procedure applied by Mplus, because these variables were considered in the SEM (Wothke, 2000). Due to the FIML procedure, the whole initial sample was used for the final analyses.

\section{Measures}

Time 1 and Time 2 questionnaires were identical except for questions on demographic variables assessed at Time 1 only. All constructs of the HAPA as well as nutrition behaviour were assessed at both points in time. If not indicated otherwise, scales are taken from Sniehotta et al. (2005) and adapted to nutrition. The response format for all scales was a four-point Likert scale ranging from 1 (disagree) to 4 (agree). Item examples are translated from German. Scale means and SDs are displayed in Table 1.

Risk awareness was measured by three items (Cronbach's $\alpha$ at Time $1=0.89$, at Time $2=0.93$ ) assessing situation-outcome expectations, for example: 'If I keep my lifestyle the way it is, there is a high likelihood that I will develop severe health problems.'

Table 1. Means and SDs of Study 1 measures $(N=469)$.

\begin{tabular}{lcccccccc}
\hline & \multicolumn{2}{c}{$\mathrm{T} 1$} & & \multicolumn{2}{c}{ T2 } & & \multicolumn{2}{c}{ Latent difference score } \\
\cline { 2 - 3 } \cline { 8 - 9 } & Mean & $S D$ & & Mean & $S D$ & & Mean & $S D$ \\
\hline Risk awareness & 2.31 & 0.90 & & 1.93 & 0.90 & & $-0.40^{* *}$ & $0.80^{* *}$ \\
Negative outcome expectancies & 1.93 & 0.69 & & 1.83 & 0.72 & & $-0.07^{*}$ & $0.46^{* *}$ \\
Self-efficacy & 3.22 & 0.53 & & 3.25 & 0.58 & & 0.02 & $0.47^{* *}$ \\
Intentions & 3.35 & 0.72 & & 3.29 & 0.75 & & $-0.09^{*}$ & $0.70^{* *}$ \\
Action planning & 3.38 & 0.61 & & 3.26 & 0.73 & & $-0.14^{* *}$ & $0.66^{* *}$ \\
Action control & 3.18 & 0.62 & & 3.00 & 0.65 & & $-0.26^{* *}$ & $0.70^{* *}$ \\
Low-fat diet & 3.22 & 0.56 & & 3.27 & 0.57 & & 0.04 & $0.37^{* *}$ \\
\hline
\end{tabular}

Notes: Time 1 and Time 2 measures are given as raw scale scores, differences are represented as latent factors. Flagged latent means and SDs are statistically significantly different from zero. $* p<0.05 ; * * p<0.01$ 
Negative outcome expectancies regarding behaviour change were assessed with three items (Cronbach's $\alpha$ at Time $1=0.80$; at Time $2=0.86$ ). The stem 'If I eat a balanced diet, ...' was followed by negative consequences, such as '... then the food is not so tasty.' or '... then I'll lose some of my quality of life.'

Self-efficacy was assessed by three items (Cronbach's $\alpha$ at Time $1=0.84$; at Time $2=0.88$ ), for example, 'I am confident that I can adjust to a balanced diet,' or 'I am confident that I can eat a healthy diet most of the time.'

Behavioural intentions were measured by a single item: 'I intend to eat a low-fat diet (e.g. low-fat meat, cheese, etc.),'

Action planning was assessed by four items (Cronbach's $\alpha$ at Time $1=0.81$; at Time $2=0.88$ ). The item stem 'I have made a detailed plan regarding...' was followed by the items (a) '. . how to change my eating habits,' (b) '... where to change my eating habits (e.g. in the cafeteria, at home, etc.),' (c) '... when (at what meals) to change my eating habits,' and (d) '... from when on I will change my eating habits.'

Action control consisted of the three sub-scales, self-monitoring, awareness of own standards, and self-regulatory effort, that were measured with three items each. The three sub-scales were used as indicators of the latent construct action control, as has been done by Sniehotta et al. (2005). The item stem 'During the past four weeks ...' was followed by items like '. . I I closely monitored my eating behaviour' for self-monitoring; '. . I had my intentions to change my eating habits often on my mind' for awareness of own standards, and '... I tried my best to act in accordance to my intentions' for self-regulatory effort. Cronbach's $\alpha$ for self-monitoring at was 0.77 and 0.77 at Time 1 and 2, respectively; 0.74 and 0.68 for awareness of own standards at Time 1 and 2; and for self-regulatory effort 0.86 and 0.87 at Time 1 and Time 2 .

Self-reported nutrition behaviour was assessed by five items from Schwarzer and Renner (2000). The response format was a four-point Likert scale ranging from 1 (disagree) to 4 (agree). Cronbach's $\alpha$ for Time 1 and for Time 2 was 0.64 and 0.71 , respectively. An item example is: 'When I eat milk products or drink milk, I choose low-fat products.'

\section{Results}

In a first step, we tested whether the assumption of strong invariance holds for this study. As described in the data analysis section, we tested a model with configurable invariance (Model 1) against a model with invariant factor loadings (Model 2), which was tested against a model with invariant factor loadings and invariant intercepts (i.e. strong invariance; Model 3). For the nested model comparisons, differences between CFI should be below 0.01 (Cheung \& Rensvold, 2002) ${ }^{3}$. The delta CFI for testing Model 1 against Model 2 was -0.001 ; delta CFI for testing Model 2 against Model 3 was -0.004 . Thus, the hypothesis assuming strong factorial invariance was not rejected.

Table 1 displays manifest means and SDs of Time 1 and Time 2 measures as well as latent difference scores. For most variables, significant changes on the mean level were observed; only the mean difference in self-efficacy and in low-fat diet did not reach statistical significance. However, for purposes of the present study mean trends are not of relevance. The crucial result refers to variance terms, which were statistically significant for all latent change factors, indicating the existence of reliable individual differences in intraindividual change. In terms of changes in nutrition behaviour $35.1 \%$ of those who participated at Time $2(n=316)$ reported a slight decrease in eating a low-fat diet, $25 \%$ did not change at all and $39.9 \%$ reported an increase in eating a low-fat diet. 
In terms of correlations of Time 1 measures with change, neither Time 1 risk awareness $(r=-0.07, p=0.25)$, nor Time 1 negative outcome expectancies $(r=-0.04, p=0.54)$, nor Time 1 self-efficacy $(r=0.03, p=0.56)$ were significantly associated with change in intentions. Time 1 intentions, in turn, was neither correlated with change in action planning $(r=-0.05, p=0.46)$, nor change in action control $(r=-0.02, p=0.76)$, nor change in low-fat diet $(r=-0.05, p=0.57)$. Time 1 self-efficacy did not display any correlations with difference scores in action planning $(r=-0.04, p=0.60)$, action control $(r=-0.07, p=0.28)$, or low-fat diet $(r=0.02, p=0.80)$. Likewise, Time 1 action planning did not result in a significant association with difference in nutrition over time $(r=-0.15$, $p=0.09)$, nor did Time 1 action control $(r=-0.14, p=0.11)$. Thus, overall, Time 1 measures were unrelated to change in intentions and nutrition behaviour. Another picture emerges when looking at correlations between latent difference scores of these variables (see Table 2 for both studies).

The structural model in Study 1 is displayed in Figure 1 and was specified as follows: latent difference scores of motivational variables risk awareness, outcome expectancies and self-efficacy were specified as predictors of the latent difference score of intentions. Change in intentions as well as change in self-efficacy were both specified as predicting change in action planning, action control and low-fat diet. Moreover, latent difference scores of action planning and action control were specified as predictors of change in low-fat diet. All Time 1 measures were allowed to correlate with each other as well as with all latent difference scores. Latent differences of action planning and action control were also allowed to correlate. The model fit was good, with CFI $=0.95, \mathrm{RMSEA}=0.036$ $(90 \% \mathrm{CI}=0.032,0.039), \chi^{2}(d f=828)=1323.39$.

Change in self-efficacy was the only significant predictor of change in intentions to eat a low-fat diet $(\beta=0.19, p=0.01)$. Contrary to our hypotheses, neither change in risk awareness $(\beta=-0.04, p=0.46)$, nor change in negative outcome expectancies $(\beta=0.10$, $p=0.13$ ) predicted change in intentions. Overall, only $4 \%$ variance in change in intentions could be explained.

Changes in action planning and action control could be explained by change in intentions (effect on action planning: $\beta=0.12, p=0.05$; effect on action control: $\beta=0.12$,

Table 2. Intercorrelations between latent difference scores for Study 1 and Study 2.

\begin{tabular}{llccccccc}
\hline & \multicolumn{7}{c}{ Study 2} \\
\cline { 3 - 8 } & & $\begin{array}{c}\text { diff } \\
\text { risk }\end{array}$ & $\begin{array}{c}\text { diff } \\
\text { oe }\end{array}$ & $\begin{array}{c}\text { diff } \\
\text { se }\end{array}$ & $\begin{array}{c}\text { diff } \\
\text { intent }\end{array}$ & $\begin{array}{c}\text { diff } \\
\text { act plan }\end{array}$ & $\begin{array}{c}\text { diff } \\
\text { act con }\end{array}$ & $\begin{array}{c}\text { diff } \\
\text { smoking }\end{array}$ \\
\hline Study 1 & diff risk & 1 & 0.17 & -0.06 & -0.01 & -0.14 & $-0.20^{* *}$ & $0.18^{*}$ \\
& diff oe & 0.03 & 1 & -0.22 & -0.13 & $-0.48^{* * *}$ & $-0.30^{* *}$ & -0.22 \\
& diff se & -0.07 & $-0.29^{* * *}$ & 1 & $0.36^{* * *}$ & $0.48^{* * *}$ & $0.42^{* * *}$ & $-0.29^{* * * *}$ \\
& diff intent & -0.05 & 0.05 & $0.16^{* *}$ & 1 & $0.35^{* * *}$ & $0.33^{* * *}$ & -0.11 \\
& diff act plan & -0.09 & $-0.18^{* *}$ & $0.37^{* * *}$ & $0.17^{* *}$ & 1 & $0.50^{* * *}$ & -0.16 \\
& diff act cont & -0.09 & -0.13 & $0.38^{* * *}$ & $0.17^{* * *}$ & $0.48^{* * *}$ & 1 & $-0.38^{* * *}$ \\
& diff fat & 0.03 & $-0.26^{* *}$ & $0.32^{* * *}$ & $0.26^{* * *}$ & $0.45^{* * *}$ & $0.51^{* * *}$ & 1 \\
\hline
\end{tabular}

Notes: Below diagonal: correlations of Study 1 (low-fat diet), above diagonal: correlations of Study 2 (smoking cessation). diff=latent difference, risk $=$ risk awareness, $o e=$ negative outcome expectancies, $s e=$ self-efficacy, intent $=$ behavioural intentions, act plan $=$ action planning, act con $=$ action control, fat $=$ low-fat diet. $N($ Study 1$)=469 ; N($ Study 2$)=441$.

${ }^{* * *} p<0.001, * * p<0.01,{ }^{*} p<0.05$. 
$p=0.04$ ), and by changes in self-efficacy (effect on action planning: $\beta=0.36, p<0.001$; effect on action control: $\beta=0.36, p<0.001$ ). Amount of variance explained in change in action planning and change in action control was $16 \%$.

Change in eating a low-fat diet was predicted by a marginally significant direct effect of change in intentions $(\beta=0.15, p=0.06)$, and significant effects of change in action planning $(\beta=0.22, p=0.04)$ and change in action control $(\beta=0.34, p<0.001)$, with action control being the strongest predictor. Change in self-efficacy did not have an effect of change in nutrition $(\beta=0.10, p=0.30)$. In terms of indirect effects on nutritional change, change in intentions resulted only via change in action control in a marginally significant indirect effect (Sobel: $1.69, p=0.09$ ), but not via change in action planning (Sobel: $1.62, p=0.11$ ). Overall, $34 \%$ of variance in change in behaviour was explained by change in intentions, action planning and action control.

\section{Study 2: Changing smoking behaviour}

\section{Design and sample}

An online study was launched in order to investigate associations between change in HAPA constructs and change in smoking behaviour. The online questionnaire was accessible via a webpage of the Department of Psychology of the University of Zurich, Switzerland. Recruitment of participants took place via an emailed invitation to undergraduate students of all departments of the University of Zurich as well as to a panel of smokers of the Institute for Social and Preventive Medicine of the University of Geneva, Switzerland. ${ }^{4}$ Moreover, invitation for participating in this study was posted at different German-language smoking-related web pages. Inclusion criterion was that participants smoked at least 1 cigarette a day. After giving informed consent online, participants filled in the first online questionnaire. Four weeks later, participants were automatically invited by email by means of the online questionnaire programme 'Netquestionnaires' to complete the second online questionnaire.

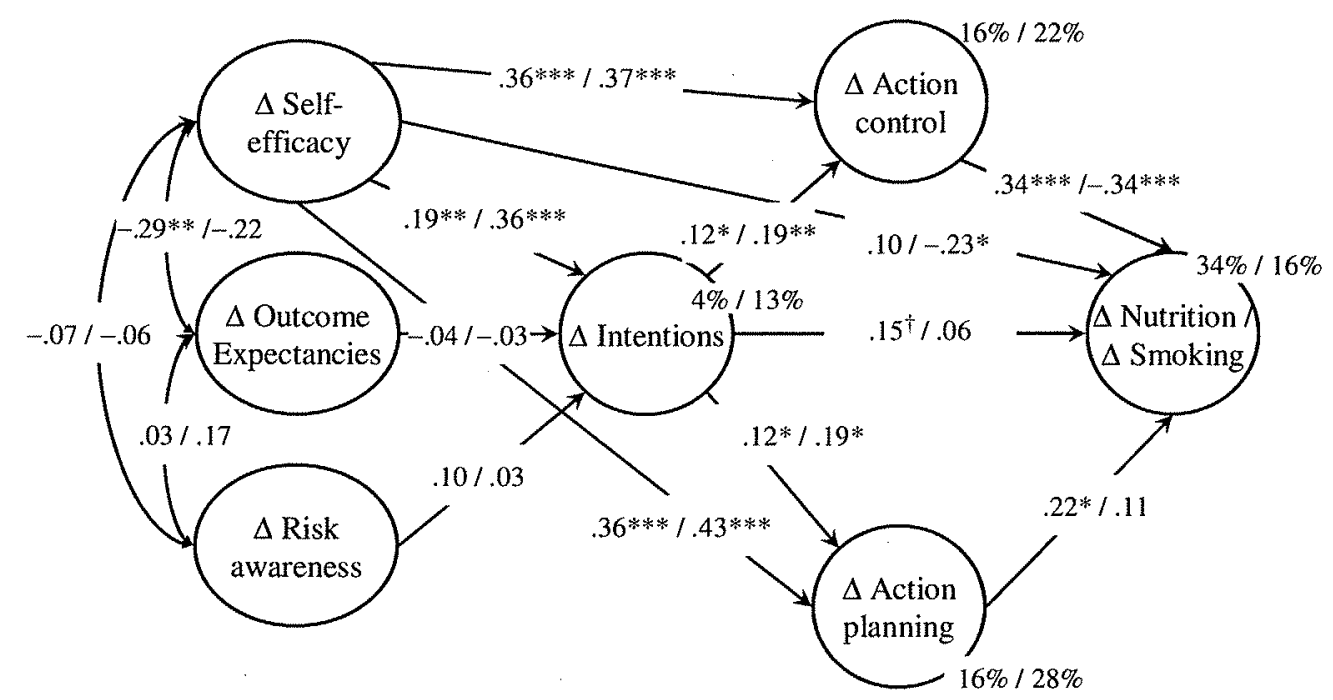

Figure 1. Structural model and fully standardised parameters for Study 1 and Study 2.

Notes: All effects of Study 1 are reported first. $\Delta$ symbolises difference scores. $N$ (Study 1$)=469$; $N$ (Study 2) $=441 .{ }^{\dagger} p<0.10,{ }^{*} p<0.05,{ }^{* *} p<0.01,{ }^{* * *} p<0.001$. 
At Time 1, a total of 441 persons completed the first questionnaire. Thereof, 227 $(51.5 \%)$ were women. Mean age of participants was 32.09 years $(S D=11.60$; range $13-66$ years). In terms of marital status, 216 individuals $(49.0 \%)$ were single, $186(42.2 \%)$ were married or living in a domestic partnership, $36(8.2 \%)$ were divorced and $3(0.7 \%)$ were widowed. Mean length of smoking was 15.14 years $(S D=11.0)$ with a mean of 15.8 $(S D=10.32)$ cigarettes daily.

The second questionnaire was completed by 235 participants $(53.3 \%)$. Dropout analyses revealed no differences on most core variables of this study. Only for Time 1 , the number of daily cigarettes smoked resulted in a significant mean difference $(F(1,439)=7.34 ; p<0.01)$ with dropouts smoking more cigarettes daily $(M=17.2$, $S D=9.8)$ than continuers $(M=14.6, S D=10.6)$. Another significant difference emerged for action planning at Time $1(F(1,429)=4.44, p<0.05)$, with dropouts reporting lower levels of action planning $(M=2.16, S D=0.85)$ than continuers $(M=2.33, S D=0.84)$. However, this systematic dropout on core variables of the study can be accounted for by the FIML procedure applied by AMOS because these variables were included in the SEM. Due to the FIML procedure, the whole initial sample was used for the final analyses.

\section{Measures}

Time 1 and Time 2 questionnaires were identical except for questions on demographic variables, assessed at Time 1 only. All constructs of the HAPA as well as smoking behaviour were assessed at both points of time. If not indicated otherwise, scales are taken from Sniehotta et al. (2005) and adapted to smoking behaviour. For most scales, response format was a four-point Likert scale ranging from 1 (disagree) to 4 (agree). Item examples are translated from German. All means and $S D$ s are displayed in Table 3.

Risk awareness was measured by three items (Cronbach's $\alpha$ at Time $1=0.89$, at Time $2=0.95$ ) assessing situation-outcome expectations, for example: 'If I keep my lifestyle the way it is, there is a high likelihood that I will develop severe health problems.'

Negative outcome expectancies regarding behaviour change were assessed with three items (Cronbach's $\alpha$ of 0.72 and 0.70 at Time 1 and 2, respectively). The stem 'If I quit smoking,...' was followed by negative consequences, such as '... then I will suffer from abstinence phenomenon' or '... then I don't know how to cope with stress situations.'

Self-efficacy was assessed by three items (Cronbach's $\alpha$ at of 0.69 and 0.75 at Time 1 and 2, respectively), for example, 'I am confident that I can quit smoking within the next months.'

Behavioural intentions were measured by a single item: 'I intend to quit smoking.'

Action planning was assessed by four items (Cronbach's $\alpha$ of 0.72 and 0.84 at Time 1 and 2 , respectively). The item stem 'I have made a detailed plan regarding...' was followed by the items (a) '. ... when not to smoke', (b) '. . . where not to smoke', (c) '. . . how to be able not to smoke' and (d) '... when I will quit smoking.'

Action control consists of the three subscales self-monitoring, awareness of own standards and self-regulatory effort that were measured with three items each. As in Study 1 , the three subscales were used as manifest indicators of the latent construct action control as has been done by Sniehotta et al. (2005). The item stem 'During the past seven days...' was followed by items like '... I closely monitored how much I smoked' for self-monitoring; '. . I had my intentions to change my smoking habits often on my mind' for awareness of own standards; and '... I tried my best to act in accordance to my intentions' for self-regulatory effort. Internal consistencies for the three subscales at both 
points of measurement were satisfactory: Cronbach's $\alpha$ for self-monitoring was 0.84 and 0.91 at Time 1 and 2, respectively; for awareness of own standards $\alpha=0.92$ and 0.68 at Time 1 and Time 2; for self-regulatory effort $\alpha=0.84$ and 0.90 at Time 1 and Time 2.

Smoking was assessed by asking 'On average, how many cigarettes do you smoke per day?'

\section{Results}

In a first step, we tested whether the assumption of strong invariance holds for Study 2 as well. As described in the data analysis section, we tested a model with configurable invariance (Model 1) against a model with invariant factor loadings (Model 2), which was tested against a model with invariant factor loadings and invariant intercepts (i.e. strong invariance; Model 3). We again relied on differences in CFI to test for measurement invariance (Cheung \& Rensvold, 2002). The delta CFI for testing Model 1 against Model 2 was zero; delta CFI for testing Model 2 against Model 3 was -0.003 . Thus, the hypothesis on strong factorial invariance was not rejected.

Table 3 displays manifest means and $S D$ s of Time 1 and Time 2 measures as well as latent difference scores. Here, only the mean difference score in daily smoking reached statistical significance. For all latent difference scores, however, significant variances emerged, indicating reliable inter-individual differences of change in all variables over time.

At Time 2, individuals smoked on average 1.71 cigarettes less than at baseline assessment. In terms of changes in smoking behaviour, $40.6 \%$ of those who participated at Time $2(n=217)$ reduced their number of cigarettes smoked, $20.6 \%$ did not change their number of cigarettes and $17.5 \%$ reported a slight increase in their smoking behaviour.

In terms of correlations of Time 1 measures with changed scores, Time 1 risk awareness was not significantly associated with change in intentions $(r=0.01, p=0.99)$, neither was Time 1 negative outcome expectancies $(r=0.12, p=0.12)$. In contrast, Time 1 self-efficacy was significantly correlated with change in intentions $(r=-0.25, p=0.001)$. Time 1 intentions was neither correlated with change in action planning $(r=-0.02, p=0.83)$ or change in action control $(r=-0.01, p=0.91)$. A significant correlation occurred, however, between Time 1 intentions and change in smoking behaviour $(r=-0.20, p=0.01)$.

Table 3. Means and SDs of Study 2 measures $(N=441)$.

\begin{tabular}{|c|c|c|c|c|c|c|}
\hline & \multicolumn{2}{|c|}{$\mathrm{T} 1$} & \multicolumn{2}{|c|}{$\mathrm{T} 2$} & \multicolumn{2}{|c|}{ Latent difference score } \\
\hline & Mean & $S D$ & Mean & $S D$ & Mean & $S D$ \\
\hline Risk awareness & 3.18 & 0.72 & 3.07 & 0.80 & -0.09 & $0.74 * *$ \\
\hline $\begin{array}{l}\text { Negative outcome } \\
\text { expectancies }\end{array}$ & 2.82 & 0.76 & 2.75 & 0.73 & -0.02 & $0.27^{* *}$ \\
\hline Self-efficacy & 2.24 & 0.83 & 2.33 & 0.89 & 0.05 & $0.64 * *$ \\
\hline Intentions & 1.67 & 0.96 & 1.69 & 0.97 & 0.04 & $0.94 * *$ \\
\hline Action planning & 2.25 & 0.84 & 2.35 & 0.92 & 0.06 & $0.83^{* *}$ \\
\hline Action control & 2.21 & 0.80 & 2.32 & 0.92 & 0.10 & $0.84 * *$ \\
\hline Smoking & 15.79 & 10.32 & 13.18 & 10.24 & $-1.71 * *$ & $4.69 * *$ \\
\hline
\end{tabular}

Notes: Time 1 and Time 2 measures are given as raw scale scores; differences are represented as latent factors. Flagged latent means and SDs are statistically significantly different from zero. $*^{* *} p<0.01$. 
Time 1 self-efficacy did not display a significant correlation with difference scores in action planning $(r=-0.12, p=0.18)$ nor with change in action control $(r=0.06, p=0.42)$. There was, however, a marginally significant association between Time 1 self-efficacy and change in smoking $(r=-0.13, p=0.08)$. Likewise, Time 1 action planning was significantly related to difference score in smoking $(r=-0.18, p=0.02)$. In contrast, Time 1 action control was not significantly associated with change in smoking $(r=-0.08, p=0.28)$. As in Study 1, correlations between latent difference scores show a quite different picture to correlations between Time 1 measures and change in intentions and behaviour (Table 2).

The structural model in Study 2 was identically specified as in Study 1 (Figure 1). Model fit was good, with $\mathrm{CFI}=0.94, \mathrm{RMSEA}=0.043(90 \% \mathrm{CI}=0.039,0.047)$, $\chi^{2}(d f=519)=942.06$. Change in self-efficacy was the only significant predictor of change in intentions to quit smoking $(\beta=0.36, p<0.01)$. Contrary to our hypotheses, neither change in risk awareness $(\beta=0.03, p=0.71)$ or change in negative outcome expectancies $(\beta=-0.03, p=0.85)$ were significantly associated with change in intentions. Overall, $13 \%$ of variance in change in intentions could be explained.

Changes in volitional factors action planning and action control could be explained by change in intentions (effect on action planning: $\beta=0.19, p=0.02$; effect on action control: $\beta=0.19, p<0.01$ ), and by changes in self-efficacy (effect on action planning: $\beta=0.43$, $p<0.001$; effect on action control: $\beta=0.37, p<0.001$ ). Amount of variance explained in change in action planning was $28 \%$ and in change in action control was $22 \%$.

Change in number of daily cigarettes smoked was predicted by change in action control $(\beta=-0.34, p<0.001)$, and change in self-efficacy $(\beta=-0.23, p<0.05)$. Neither change in intentions $(\beta=0.06, p=0.45)$, nor change in action planning $(\beta=0.11, p=0.33)$ were significantly related to change in smoking. Change in self-efficacy was also marginally indirectly related to change in smoking via change in action control (Sobel: -1.78 , $p=0.08$ ). Overall, $16 \%$ of variance in change in behaviour was explained.

\section{General discussion}

Our research demonstrated the importance of investigating the associations between change in motivational and volitional constructs and change in intentions and behaviour. Both studies showed largely the same prediction patterns in that changes in motivational predictors were more strongly associated with changes in intentions than baseline measures in motivational predictors and that changes in volitional measures (i.e. action planning, action control), intentions and self-efficacy were more strongly associated with change in behaviour than baseline measures of those predictor variables. These similar results emerged although implemented with different target behaviours (i.e. low-fat diet and smoking cessation), different time spans (3 months and 4 weeks), and different samples, emphasising the validity of the chosen approach.

The substantial similarity of results across Study 1 and 2 is not only convincing when considering the difference between behaviours, but also when considering differences across both samples. While Study 1 participants were highly motivated (i.e. mean intentions at Time 1 were $3.35, S D=0.72$ on a scale from 1 to 4 ), respondents in Study 2 did not report high intentions at Time $1(M=1.67, S D=0.96$ on a scale from 1 to 4$)$. This also speaks in favour of the validity of the HAPA across samples of different motivational starting points.

In both studies change in risk awareness and change in negative outcome expectancies were not associated with change in intentions. For outcome expectancies, 
this is in contrast with results of other studies (e.g. Bandura, 1997). Risk awareness, however, has often been demonstrated to be a weak predictor in studies on the HAPA (e.g. Schwarzer \& Renner, 2000).

In line with our assumptions, change in self-efficacy was an important predictor of change in intentions and of change in behaviour. For the latter, this was qualified by a direct and several indirect effects via volitional variables and intentions in both studies. These results demonstrate the importance of self-efficacy in the process of health behaviour change (cf Bandura, 1997) and are in line with previous research in health behaviour change (e.g. Kok, deVries, Mudde, \& Strecher, 1991; Luszczynska, Tryburcy, \& Schwarzer, 2007).

Considering the bivariate correlations between change in intentions and change in behaviour, both studies demonstrated that change in intentions alone would not have been able to explain $34 \%$ of variance in change in a low-fat diet nor $16 \%$ of change in smoking behaviour. To a certain amount, this might be due to the fact that intentions were measured by a single item. However, the finding that intentions alone are not sufficient for a satisfying prediction of behaviour is in line with the literature on the intention-behaviour gap (e.g. Sheeran, 2002) and with other studies on the HAPA that used multiple indicators for intentions (e.g. Sniehotta et al., 2005). Thus, inclusion of volitional variables proved once again useful. This is in line with several recent studies on the HAPA (e.g. Schwarzer et al., 2007). The present article, however, is the first to demonstrate associations between changes in motivational and volitional variables with changes in intentions and in behaviour by using a non-experimental correlational design.

The positive association between change in action planning and change in behaviour in Study 1 is in line with several studies on the effects of implementation intentions on nutrition behaviour (e.g. Luszczynska et al., 2007). In Study 2, no significant association emerged between change in action planning and change in smoking behaviour. This is contrary to our hypotheses as well as to most results reported in the literature on positive associations between action planning and change in different health behaviours (e.g., Gollwitzer \& Sheeran, 2006). In studies on the effects of action planning on smoking cessation, however, results are equivocal. Higgins and Conner (2003), for example, could not find any significant difference between an implementation intention group and a control group in terms of number of cigarettes smoked. In the present study, planning items assessed amount of planning not to smoke. Likewise, in the study of Higgins and Conner (2003), target behaviour was to resist smoking, that is, not to smoke. A possible explanation for the lack of effects of implementation intentions on behaviours that need to be given up is that plans for not doing something might be not comparable to plans for doing something. Future studies should, therefore, examine this issue more closely.

To our knowledge, this study was also the first to demonstrate the usefulness of change in action control for change in nutrition and smoking cessation. Change in action control displayed the strongest direct effect on change in behaviour in both studies. Its usefulness in interventions on change in dental flossing has already been demonstrated (e.g. Schüz et al., 2007). Within the research on smoking cessation, one facet of action control, selfmonitoring, is among the most prominent concepts for smoking cessation (e.g. Fisher, Lichtenstein, Haire-Joshu, \& Morgan, 1993). Thus, action control is a promising target for interventions for changing different health behaviours.

\section{Advantages of measuring change}

Most studies that test for associations between Time 1 measures with Time 2 behaviour or change in behaviour from Time 1 to Time 2 interpret their results as evidence for what 
social-cognitive variables need to be changed by interventions in order to foster behaviour change. However, as our data demonstrates, prediction patterns of change in motivational and volitional variables for latent difference scores in intentions and behaviour differed quite substantially from correlations of Time 1 measures with change in intentions and change in behaviour. Thus, as most interventions are based on the assumption that changing social-cognitive variables will lead to change in behaviour, the present approach constitutes a step forward to the question what variables should indeed be changed in an intervention.

Moreover, testing for associations between change indices instead of testing for baseline associations with change in criteria may be of particular importance in studying behaviours that do not have a clear baseline, as for example, in terms of a starting point of behavioural change, but covered a rather optional time period during ongoing behaviour change.

Furthermore, the present results have important methodological implications. Testing predictor variables only at Time 1 might blur major relations between variables due to different response sets persons have (Maydeu-Olivares \& Coffman, 2006). For example, when Person A tends to respond positively to all items, whereas Person B tends to respond negatively to all items, associations between variables could only emerge due to these response sets. When analysing associations between difference scores, however, these possible methodological artefacts are accounted for, because by subtraction response sets are likely cancelled down.

\section{Limitations and outlook}

The present investigation has its limitations. First, in terms of causality, we can not claim that change in motivational predictors caused change in intentions, nor that change in volitional predictors caused change in behaviour. Indeed, it might be as well the other way round: according to Bandura (1997), for example, mastery experience with certain behaviour is a source of self-efficacy beliefs. We can conclude however, that change in social-cognitive variables is accompanied by change in behaviour. Furthermore, as the SEM results demonstrated, these associations were in line with the theoretical expectations specified in the HAPA model.

Second, behavioural intentions were measured by using a single item only. Although in line with other studies that used multiple indicators for intentions (Sniehotta et al., 2005), this might have contributed to the weak prediction of intentions alone for behaviour. In future studies, multiple indicators for intentions should be assessed.

A third limitation of both studies is the use of self-reported behaviour as the main outcome variable. However, self-reported smoking might be seen as a rather accurate measure (e.g. Bernaards, Twisk, van Mechelen, Snel, \& Kemper, 2004). For self-reported nutrition, under-reporting of actual behaviour is a known problem in overweight people (Howat et al., 1994). However, online studies have the advantage of higher anonymity compared to common paper and pencil studies, and as a consequence, are less prone to trigger socially desired responses (e.g. Joinson, 1999).

Fourth, the measurement of the constructs might face some problems with regard to the correspondence principle (Ajzen, 1991). Some of the predictors in both studies were assessed at a more general level (e.g. risk awareness) than others (e.g. intentions or behaviour). This might have influenced the predictive power of these predictor variables negatively, as prediction is assumed to be highest when predictor and criterion are 
measured on the same level of generality/specificity. Future studies might want to solve this problem by using the same level of specificity for all predictors used in the study in order to ensure comparability across predictor variables.

This article has several implications for future research. Examining associations with change in motivational and volitional variables with change in behaviour allows for better insight into processes of health behaviour change. This is important for future interventions and should thus be implemented more often in two-wave studies, especially in those that do not contain a clear baseline. Based on the results of the present research, interventions should aim at fostering self-efficacy, action planning and action control for fostering change in nutrition behaviour. For example, action control can be increased by keeping a diary on one's daily behaviour. Especially for smoking cessation, action control may be of crucial importance (e.g. Fisher et al., 1993). Associations between action planning and smoking cessation need further investigations. Moreover, in terms of planning, it should be investigated whether there is a difference in effectiveness for behaviours that need to be given up (e.g. smoking cessation) and for behaviours that need to be initiated.

\section{Notes}

1. We would like to thank Christian Dettwiler and Ruth Ellenberger for their support with data collection.

2. Note that $16 \%$ is most likely an underestimation of the return rate because a large number of the registered eBalance participants were not active and only active members could have seen the invitation to the study on the website.

3. We have relied on differences in CFI to assess factorial invariance because as Cheung and Renswold (2002) have demonstrated the conventional $\chi^{2}$ difference test is prone to the same problems as the conventional $\chi^{2}$ test in studies aimed at investigating measurement invariance. Based on extensive simulations, these authors have recommended testing for differences in CFI to assess the degree of invariance given.

4. We would like to thank J.F. Etter for supporting data collection.

\section{References}

Ajzen, I. (1991). The theory of planned behavior. Organizational Behavior and Human Decision Processes, 50, 179-211.

Arbuckle, J.L. (1996). Full information estimation in the presence of incomplete data. In G.A. Marcoulides \& R.E. Schumacker (Eds.), Advanced structural equation modeling (pp. 243-277). Mahwah, NJ: Erlbaum.

Ayyad, C., \& Andersen, T. (2000). Long-term efficacy of dietary treatment of obesity: A systemativ review of studies published between 1931 and 1999. Obesity Reviews, 1, 113-119.

Bandura, A. (1997). Self-efficacy: The exercise of control. New York: Freeman.

Baumeister, R.F., Heatherton, T.F., \& Tice, D. (1994). Losing control: How and why people fail at self-regulation. San Diego, CA: Academic Press.

Bereiter, C. (1963). Some persisting dilemmas in the measurement of change. In C.W. Harris (Ed.), Problems in measuring change (pp. 3-20). Madison, WI: The University of Wisconsin Press.

Bernaards, C.M., Twisk, J.W.R., van Mechelen, W., Snel, J., \& Kemper, H.C.G. (2004). Comparison between self-report and a dipstick method (NicCheck $\left.{ }^{\circledR}\right)$ to assess nicotine intake. European Addiction Research, 4, 163-167.

Carver, C.S., \& Scheier, M.F. (1998). On the self-regulation of behavior. New York: Cambridge University Press. 
Cheung, G.W., \& Rensvold, R.B. (2002). Evaluating goodness-of-fit indexes for testing measurement invariance. Structural Equation Modeling, 9, 233-255.

Enders, C.K., \& Bandalos, D.L. (2001). The relative performance of Full Information Maximum Likelihood Estimation for missing data in structural equation models. Structural Equation Modeling, 8, 430-457.

Fisher, E.B., Lichtenstein, E., Haire-Joshu, D., \& Morgan, G.D. (1993). Methods, successes, and failures of smoking cessation programs. Anmual Review of Medicine, 44, 481-513.

Gollwitzer, P.M. (1999). Implementation intentions. Strong effects of simple plans. American Psychologist, 54, 493-503.

Gollwitzer, P.M., \& Sheeran, P. (2006). Implementation intentions and goal achievement: A meta-analysis of effects and processes. Advances in Experimental Social Psychology, 38, 69-119.

Higgins, A., \& Conner, M. (2003). Understanding adolescent smoking: The role of the Theory of Planned Behaviour and implementation intentions. Psychology, Health, \& Medicine, 8, 173-186.

Howat, P.M., Mohan, R., Champagne, C., Monlezun, C., Wozniak, P., \& Bray, G.A. (1994). Validity and reliability of reported dietary intake data. Journal of the American Dietetic Association, 94, 169-173.

Joinson, A. (1999). Social desirability, anonymity, and internet-based questionnaires. Behavior Research Methods, Instruments \& Computers, 31(3), 433-438.

Jöreskog, K.G. (1969). A general approach to confirmatory maximum likelihood factor analysis. Psychometrika, 34, 183-202.

Jöreskog, K.G. (1979). Statistical estimation of structural models in longitudinal investigations. In J.R. Nesselroade \& B. Baltes (Eds.), Longitudinal research in the study of behavior and development (pp. 303-351). New York: Academic Press.

Keller, R., Willi, M., Krebs, H., \& Hornung, R. (2004). Tabakmonitoring - Schweizerische Umfrage zum Tabakkonsum. Auför - bzw. Reduktionsbereitschaft der Raucherinnen und Raucher in der Schweiz. Im Auftrag des Bundesamtes für Gesundheit, Facheinheit Sucht und Aids [Swiss Tobacco Monitoring System. Willingness to quit/reduce of Swiss Smokers]. Zürich: Psychologisches Institut der Universität Zürich, Sozial- und Gesundheitspsychologie. Retrieved December 19, 2007, from http://www.bag.admin.ch/themen/drogen/00041/00611/03648/index.html?lang=de

Keller, R., Krebs, H., Radtke, T. \& Hornung, R. (2007). Der Tabakkonsum der Schweizer Wohnbevölkerung in den Jahren 2001 bis 2006. Tabakmonitoring - Schweizerische Umfrage zum Tabakkonsum [Tobacco Consumption of the Swiss resident population during $2001-2006$. Swiss Tobacco Monitoring System]. Im Auftrag des Bundesamtes für Gesundheit, Gesundheitspolitik, Fachstelle Tabakpräventionsfonds. Zürich: Psychologisches Institut der Universität Zürich, Sozial- und Gesundheitspsychologie. Retrieved December 19, 2007, from http://www.bag.ad$\mathrm{min} . \mathrm{ch} /$ themen/drogen/00041/00611/03648/index.html?lang=de

Kline, R.B. (2005). Principles and practice of structural equation modelling. New York: Guilford Press.

Kok, G., DeVries, H., Mudde, A.N., \& Strecher, V.J. (1991). Planned health education and the role of self-efficacy: Dutch research. Health Education Research, 6, 231-238.

Lippke, S., Ziegelmann, J.P., \& Schwarzer, R. (2004). Behavioral intentions and action plans promote physical exercise: A longitudinal study with orthopedic rehabilitation patients. Journal of Sport \& Exercise Psychology, 26, 470-483.

Little, R.J.A., \& Rubin, D.B. (2002). Statistical analysis with missing data (2nd ed.). Hoboken, NJ: Wiley.

Luszczynska, A., Tryburcy, M., \& Schwarzer, R. (2007). Improving fruit and vegetable consumption: A self-efficacy intervention compared with a combined self-efficacy and planning intervention. Health Education Research, 22, 630-638.

Maddux, J.E., \& Rogers, R.W. (1983). Protection motivation and self-efficacy: A revised theory of fear appeals and attitude change. Journal of Experimental Social Psychology, 19, 469-479. 
Maydeu-Olivares, A., \& Coffman, D.L. (2006). Random intercept item factor analysis. Psychological Methods, 11, 344-362.

McArdle, J.J. (2001). A latent difference score approach to longitudinal dynamic structural analyses. In R. Cudeck, S. du Toit \& D. Sorbom (Eds.), Structural equation modeling: Present and future (pp. 342-380). Lincolnwood, IL: Scientific Software International.

Meredith, W. (1993). Measurement invariance, factor analysis and factorial invariance. Psychometrika, 58, 525-543.

Mokdad, A., Marks, J., Stroup, D., \& Gerberding, J. (2004). Actual causes of death in the United States, 2000. Journal of American Medical Association, 291, 1238-1245.

Mokdad, A., Marks, J., Stroup, D., \& Gerberding, J. (2005). Correction: Actual causes of death in the United States, 2000 (letter). Journal of American Medical Association, 293, 293-294.

Muthén, L.K., \& Muthén, B.O. (1998-2006). Mplus user's guide (4th ed.). Los Angeles, CA: Muthén $\&$ Muthén.

Plewis, I. (1985). Analysing change: Measurement and explanation using longitudinal data. Chichester: Wiley.

Ruiter, R.A.C., Abraham, C., \& Kok, G. (2001). Scary warnings and rational precautions: A review of the psychology of fear appeals. Psychology and Health, 16, 613-630.

Schüz, B., Sniehotta, F.F., \& Schwarzer, R. (2007). Behavioral stages and self-regulation: Testing stage-specific effects of an action control intervention on dental flossing behavior. Health Education Research, 22, 332-241.

Schwarzer, R. (1992). Self-efficacy in the adoption and maintenance of health behaviors: Theoretical approaches and a new model. In R. Schwarzer (Ed.), Self-efficacy: Thought control of action (pp. 217-243). Washington, DC: Hemisphere.

Schwarzer, R., \& Renner, B. (2000). Social-cognitive predictors of health behaviour: Action selfefficacy and coping self-efficacy. Health Psychology, 19, 487-495.

Schwarzer, R., Schüz, B., Ziegelmann, J.P., Lippke, S., Luszczynska, A., \& Scholz, U. (2007). Adoption and maintenance of four health behaviors: Theory-guided longitudinal studies on dental flossing, seat belt use, dietary behavior, and physical activity. Annals of Behavioral Medicine, 33, 156-166.

Schweizerische Gesellschaft für Ernährung. (2007). Recommendations for healthy, tasty eating and drinking for adults: Food pyramid. Retrieved December 20, 2007, from http://www.sgessn.ch/science/scientific_publications/ssn_publications/food_pyramid/english/food_pyramid_ 65 engl.pdf

Sheeran, P. (2002). Intention-behavior relations: A conceptual and empirical review. In M. Hewstone \& W. Stroebe (Eds.), European review of social psychology (Vol. 12, pp. 1-36). Chichester, England: Wiley.

Sniehotta, F.F., Scholz, U., \& Schwarzer, R. (2005). Bridging the intention-behaviour gap: Planning, self-efficacy, and action control in the adoption and maintenance of physical exercise. Psychology \& Health, 20, 143-160.

Ward, G., \& Morris, R. (2005). Introduction to the psychology of planning. In R. Morris \& G. Ward (Eds.), The cognitive psychology of planning (pp. 1-32). Hove: Psychology Press.

Webb, T., \& Sheeran, P. (2006). Does changing behavioral intentions engender behavior change? A meta-analysis of the experimental evidence. Psychological Bulletin, 132, 249-268.

Weinstein, N.D. (2003). Exploring the links between risk perceptions and preventive health behavior. In J. Suls \& K. Wallston (Eds.), Social psychological foundations of health and illness (pp. 22-53). Oxford, England: Blackwell.

World Health Organisation (2006). Obesity and overweight. Retrieved April 11, 2007, from http:// www.who.int/mediacentre/factsheets/fs311/en/print.html

Wothke, W. (2000). Longitudinal and multiple-group modeling with missing data. In T.D. Little, K.U. Schnabel \& J. Baumert (Eds.), Modeling longitudinal and multilevel data: Practical issues, applied approaches, and specific examples (pp. 219-240). Mahwah, NJ: Lawrence Erlbaum Associates. 